\title{
Females do count: Documenting Chironomidae (Diptera) species diversity using DNA barcoding
}

\author{
Torbjørn Ekrem • Elisabeth Stur • Paul D. N. Hebert
}

Received: 19 April 2010 / Accepted: 8 October 2010 /Published online: 23 October 2010

(C) The Author(s) 2010. This article is published with open access at Springerlink.com

\begin{abstract}
Because the family Chironomidae, or non-biting midges, is one of the most species-rich groups of macroinvertebrates in freshwater habitats, species-level identifications of chironomids are important for biodiversity assessments in these ecosystems. Morphology-based species identifications from adult female chironomids usually are considerably more difficult than from adult males, or even impossible; thus, the females are often neglected in community assessments. We used DNA barcoding to investigate how inclusion of the females influenced the species count from springs and spring brooks at Sølendet Nature Reserve in Central Norway. By means of the barcodes we were able to identify $77.6 \%$ of the females to species by associating them with males from the study site or from other regions, whereas the remaining, unassociated females could be identified to genus level only. The number of recorded species increased by $27 \%$ when females were included. We also found that DNA barcoding is effective for the detection of taxonomically challenging species and species groups. Using DNA barcoding in combination with traditional taxonomy, we recognised at least five species new to science and three species and one genus new to Norway.
\end{abstract}

\footnotetext{
T. Ekrem $(\bowtie) \cdot$ E. Stur

Norwegian University of Science and Technology,

Museum of Natural History and Archaeology,

NO-7491 Trondheim, Norway

e-mail: Torbjorn.Ekrem@vm.ntnu.no

E. Stur

e-mail: Elisabeth.Stur@vm.ntnu.no

P. D. N. Hebert

Biodiversity Institute of Ontario, University of Guelph,

579 Gordon Street,

Guelph, Ontario, Canada N1G 2W1

e-mail: phebert@uoguelph.ca
}

Keywords DNA barcoding · Biodiversity · Insects . Freshwater $\cdot$ Diptera $\cdot$ Chironomidae

\section{Introduction}

The family Chironomidae (Diptera), or non-biting midges, is a species-rich group of flies that includes more than 1200 valid species in Europe (Sæther and Spies 2004) and an estimated more than 10,000 species worldwide (Armitage et al. 1995). The group is very ecologically diverse, with larvae recorded from terrestrial, semi-terrestrial and aquatic environments. Among the aquatic species most are restricted to freshwater habitats, but several lineages have independently colonised marine environments. Chironomids are widely distributed and present in all geographical regions, including the Antarctic. Many areas remain largely under-sampled and the taxonomy of numerous, even European, groups still remains to be resolved.

Despite being one of the most species-rich families of freshwater invertebrates, non-biting midges are often neglected in biodiversity studies and biomonitoring of aquatic ecosystems. The relative scarcity of taxonomic specialists and frequent difficulties with gaining specieslevel identifications, especially for larvae and adult females, are important reasons for this neglect. It is now well accepted that species-level identifications should be the default in freshwater bioassessments, in order to maximise the information content available for statistical analyses and to ensure comprehensive summaries of biotic compositions (Jones 2008 and references therein). However, the frequent necessity to prepare microscopy slides for species identifications in Chironomidae makes inclusion of this group in freshwater biomonitoring by traditional means comparatively labour-intensive. 
The use of chironomid pupal exuviae has been shown to be effective in the monitoring of boreal rivers (Raunio and Muotka 2005; Raunio et al. 2007), and has also been applied to springs and spring brooks (Blackwood et al. 1995). However, since many chironomid species have a short emergence period, frequent sampling is necessary to gain a complete picture of local and regional species diversity (Raunio and Muotka 2005). Moreover, the collection of such exuviae from terrestrial or semiterrestrial habitats is difficult, since they often stick to the vegetation or substrate. As a consequence, surveys of pupal exuviae almost certainly lead to underrepresentation of such taxa in inventories of moist habitats (e.g. streambeds and helocrene springs). It is therefore advisable to sample adult chironomids if the goal is to get as complete a list of species as possible. Various traps for flying insects collect continuously, and Malaise traps and emergence traps are well suited to collect flying chironomids. They do require some attention, however, and depending on the productivity of the area, must be emptied every one to two weeks. In our experience, this is especially important when DNA degradation is to be avoided.

Faunistic studies that include adult chironomids tend to focus on males (e.g. Aagaard et al. 2004; Stur et al. 2005), with the tacit assumption that they represent all the sampled species at the locality. Because many species have been described from males only, and even described females often are difficult or impossible to identify, the latter have suffered a general lack of taxonomic attention. Consequently, the focus on males in species inventories of adult chironomids is understandable and not easily overcome. However, several chironomid species are known to be at least facultatively parthenogenetic (e.g. Armitage et al. 1995; Langton 1999; Scholl 1960), and there is a greater chance that these, as well as sexually reproducing species occurring in low abundance, will remain undetected if only males are analysed. This is particularly true for studies with low sample sizes or if rare species have female-biased sex ratios. The study presented here, as well as an ongoing study using Malaise traps along an alpineboreal watershed (unpublished), documents that the total number of females often greatly exceeds that of males. Thus, one should expect that inclusion of female chironomids in faunistic inventories of freshwater ecosystems will increase the number of species sampled.

DNA barcoding utilises a short gene fragment to identify species. It represents a shift from the near-exclusive reliance on morphological characters for the identification and detection of species to an approach that includes molecular characters in species discrimination. The $648 \mathrm{bp}$ segment of the mitochondrial cytochrome c oxidase subunit 1 gene (COI) proposed by Hebert et al. (2003) has now gained general acceptance as the barcode region for most groups in the animal kingdom. Numerous studies have established its effectiveness in species identification in various animal groups (e.g. Golding et al. 2009 and references therein), including the family Chironomidae (Carew et al. 2005, 2007; Ekrem et al. 2007; Pfenninger et al. 2007; Sinclair and Gresens 2008). An acknowledged advantage of DNA barcoding is the possibility to easily associate different life stages of the same species (Blaxter 2004; Ekrem et al. 2007; Stoeckle 2003). This is particularly valuable to the study of organisms with morphologically inseparable immature stages, and of taxa which are difficult to rear, such as many freshwater insects adapted to cold, ultra-oligotrophic or other special habitats that are hard to imitate in the laboratory. Several studies have demonstrated the usefulness of DNA barcodes to associate life stages in practice (e.g. Caterino and Tishechkin 2006; Pegg et al. 2006; Zhou et al. 2009); Carew et al. (2005) and Ekrem et al. (2007) have found that partial COI gene sequences can be used to link different life stages of the same species in Chironomidae.

The effectiveness of DNA barcoding to discriminate between biological species has been questioned by several authors (e.g. Rubinoff et al. 2006 and references therein). The presence of mitochondrial pseudogenes (Bensasson et al. 2001) or of bacteria such as Wolbachia (e.g. Linares et al. 2009) can pose problems if barcode sequences are not examined for stop codons or tested for known contaminants. Moreover, the presence of incomplete lineage sorting can result in species-level paraphyly and polyphyly (Funk and Omland 2003), leaving delineation of species by means of monophyletic barcode clusters difficult. Although none of these challenges appears to pose problems with the use of COI sequences in DNA barcoding of chironomids (Carew et al. 2005, 2007; Ekrem et al. 2007; Pfenninger et al. 2007; Sinclair and Gresens 2008; present study), high interspecific variation in COI has made this marker unreliable for phylogenetic analyses of Chironomidae genera (Ekrem et al. 2010). As a result, large genera are often not reconstructed as monophyletic by COI, and taxonomic identification above the species level is not advisable for unknowns unless there is a close match to a species in the barcode library (Ekrem et al. 2007). The comparatively rapid pace of COI evolution is, however, desirable for DNA barcoding, because large interspecific variation aids the diagnosis of species clusters. In the study by Ekrem et al. (2007) the maximum pairwise distance within the subtribe Tanytarsina of the subfamily Chironominae was 25\% (mean 16.2\%) and larger values have been observed in other insect groups (Zhou et al. 2009). It is perhaps therefore not surprising that the observed efficiency of DNA barcoding to discriminate between species in insect families with maximum genetic distances of 21-35\% (Zhou et al. 2009) is higher than in 
an insect family with a maximum distance of $10 \%$ (Wiemers and Fiedler 2007).

Although the taxonomy of European Chironomidae is reasonably advanced, new species and species groups still are regularly added (e.g. Giłka and Paasivirta 2008; Stur and Ekrem 2006; Sæther 2000). The morphological differences between closely related species are often subtle, and information from more than one life stage as well as data on behaviour and ecology frequently are of great help in species delimitation. In this regard, DNA barcodes have been shown to provide a set of useful characters that, together with morphological or cytogenetic data, can be used to better understand taxonomic boundaries in Chironomidae (Ekrem et al. 2007; Pfenninger et al. 2007; Sinclair and Gresens 2008).

In the present study, we employ DNA barcoding to investigate whether the inclusion of adult females substantially increases the species count in an inventory of cold water springs and spring brooks. We also provide new information on some taxonomically challenging species and species groups. On a local level our data represent new knowledge on the chironomid community in selected habitats at Sølendet Nature Reserve. In a wider context they make a contribution to the overall effort to build a comprehensive barcode library for eukaryotes.

\section{Material and methods}

The study area at Sølendet Nature Reserve is located in Central Norway $\left(\mathrm{N} 62.68^{\circ} \mathrm{E} 11.83^{\circ}\right)$ at $700-800 \mathrm{~m}$ a.s.l. The reserve itself covers 306 ha; about half of the area is characterised as rich fen, the remainder is a mixture of grassland and heath (Moen 1990). There are more than 50 registered freshwater springs at Sølendet, varying from slow seepages to true rheocrenes (Moen 1990). We placed three emergence traps, each covering $0.25 \mathrm{~m}^{2}$, over three well separated springs. Three additional traps were placed over the respective spring brooks, $10-20 \mathrm{~m}$ downstream from the source. All traps used $80-85 \%$ ethanol in the collectors and were emptied at 2-3 week intervals in the periods from 27 May to 9 October 2005, 25 May to 31 August 2006, and 2 May to 2 July 2007. Two of the traps were moved to a different (more suitable) spring after the 2005 season.

Male and female chironomids were separated under a stereo microscope and as many different male morphotypes as possible were qualitatively selected for further analysis. Different morphotypes were recognised based on variation in all observable morphological traits such as size, coloration, venation, setation, genital structures, and shapes of antennae and legs. Tissue (one to three legs, depending on size) was sampled from three to five specimens of each male morphotype and shipped to the Canadian Centre for DNA Barcoding at the University of Guelph (CCDB, www. dnabarcoding.ca) for sequence analysis. For some morphotypes, only one or two specimens could be retrieved. After leg removal, the remainder of most specimens was macerated in $\mathrm{KOH}$ and slide-mounted in Euparal for species identification with a compound microscope. We apply the term 'morphospecies' to specimens that we were able to identify, name and group based on morphology after slide-mounting. Morphological identification relied on available keys, taxonomic revisions and original descriptions (e.g. Brundin 1947, 1949; Langton and Pinder 2007; Sæther 1977, 1983, 1985, 1989, 1990; Sæther and Sublette 1983; Stur and Ekrem 2006), as well as on specimens in reference collections.

To see whether we could associate females to all species by the use of DNA barcodes, all recognizably different female morphotypes were sampled and analysed in the same way. Additional specimens are still preserved in ethanol and stored at $-20^{\circ} \mathrm{C}$. The material is deposited at the Museum of Natural History and Archaeology in Trondheim, Norway, marked with Barcode of Life Data Systems (BOLD; see Ratnasingham and Hebert 2007) sample identification numbers (see the published BOLD project Chironomids of Sølendet, CHSOE). GenBank Accession numbers are: AM398747, AM398748, AM398743, AM398768, AM398732, AM398733, AM398769, HM406100HM406121, and HQ105015-HQ105388.

DNA extraction, PCR and bi-directional sequencing followed standard protocols and primers at the CCDB (http://www.dnabarcoding.ca/pa/ge/research/protocols) and partial COI sequences; all metadata are registered in BOLD. The primer pairs used for PCR and sequencing were LCO1490 + HCO2198 (Folmer et al. 1994), and LepF1 + LepR1 (Hebert et al. 2004). Only sequences with lengths above $200 \mathrm{bp}$ were used in the analyses.

The taxon ID-tree was produced by Neighbour Joining (NJ) analysis on Kimura 2-parameter (K2P) distances, using the analytical tool in BOLD as well as MEGA4 (Tamura et al. 2007), and figured in FigTree 1.2.2 (Rambaut 2009). Boostrap analysis was performed with 1000 pseudoreplicates. The taxon ID-tree is not a representation of the most likely phylogeny of the included taxa, but rather a graphical representation of the genetic differences between sequences and clusters of sequences in the dataset. We do not investigate the relationships between species and genera in this study, as COI is too variable for detailed phylogenetic analysis in Chironomidae (Ekrem et al. 2010). Nevertheless, we have performed phylogenetic analyses using Bayesian inference on this dataset to investigate whether a character-based method creates the same barcode clusters as NJ. For this purpose we used the program MrBayes 3.1.2 (Huelsenbeck and Ronquist 2001; Ronquist 
and Huelsenbeck 2003), running four chains for 10 million generations and flat priors on the Computational Biology Service Unit of Cornell University (http://cbsuapps.tc. cornell.edu/index.aspx). The first 3 million generations were considered as 'burn-in' and not included in the consensus tree. The K2P model is used for the NJ analysis as it has been the standard model of substitution in other barcode studies and thus allows a broader comparison across studies. We did, however, run the Bayesian analyses using the GTR + G + I model, as the latter has been found the most appropriate model of nucleotide substitution for our dataset by the hierarchical likelihood ratio test in Modeltest 3.7 (Posada and Crandall 1998).

To investigate whether unmatched female sequences from Sølendet were similar to sequences recorded from male chironomids from other areas, we compared the former to the full Chironomidae dataset in BOLD. For assumption of species identity, the female-to-male sequence difference had to be no greater than $4 \%$, and in the taxon ID-tree such female sequences had to form a monophyletic group with the corresponding male reference sequences.

The taxon matrix and accompanying data can be downloaded from TreeBASE (http://purl.org/phylo/tree base/phylows/study/TB2:S10724).

\section{Results and discussion}

Species diversity and DNA barcoding

In total, almost twice as many females (8835) as males (4510) were collected in the emergence traps. Although the larger number of females likely reflects a biased sex ratio, their dominance may also indicate the presence of parthenogenetic species (e.g. Lindeberg 1971).

357 males, 113 females and one hermaphrodite were selected for DNA barcode analysis. PCR and sequencing success was lower than usual for chironomids (Ekrem et al. 2007; authors' unpublished data), averaging $85.4 \%$ for males and $86.7 \%$ for females. The failure to recover sequences from approximately $15 \%$ of the specimens likely reflects DNA degradation. The emergence traps were placed in an open landscape and only emptied every 23 weeks; considerable ethanol evaporation occurred during periods of warm, sunny weather. Furthermore, the collectors in the emergence traps had clear lids; thus it is likely that exposure to UV radiation and heat caused DNA fragmentation in some specimens.

Bayesian analyses of the dataset using the GTR $+\mathrm{G}+\mathrm{I}$ substitution model produced the same species clusters as NJ analysis using $\mathrm{K} 2 \mathrm{P}$, all with posterior probabilities of 1.0 but with slightly different branch lengths (trees available from TreeBASE at: http://purl.org/phylo/treebase/phylows/ study/TB2:S10724).

Most of the 304 males that were sequenced could be identified to species using the available literature; all 71 species discriminated by morphology (morphospecies) were also discriminated by their barcodes (Fig. 1). In addition, DNA barcode divergences $(>6 \%)$ indicated that we had collected three rather than just one species of Krenopelopia (Fig. 1). Males of species in this genus are notoriously difficult and perhaps impossible to separate at species level, and some species are known as pupae only (Fittkau 1962).

No more than about two thirds $(64 / 98,65.3 \%)$ of the females that were sequenced belonged to a species that was also detected among the males at our study site. In addition, we could genetically associate 12 female specimens with males from 10 species recorded from other regions. This left 22 female specimens (22.4\%) without associated males which morphologically could not be identified using existing literature. Females of congeneric Chironomidae species often are so similar in morphology that some remain impossible to separate even after slide-mounting. Considering that we used a morphotype approach to select specimens for our analyses, it is likely that we failed to separate some females in complexes of cryptic species. As a result, the number of species represented by females likely is a conservative estimate with regard to the impact of including females in biodiversity assessments.

Barcoding results (Table 1) indicate the presence of 100 Chironomidae species in our collections from Sølendet. Of these, 32 species are represented by both sexes, 41 species only by males, and 27 species only by females. Thus, despite the considerably lower sample size for sequenced females, $27 \%$ of the species were only represented by this sex.

In other words, if a qualitative faunistic study on the chironomid communities in the springs of Sølendet were based solely on males from the available samples, we would miss $27 \%$ of the species diversity. Arguably, more species would also be detected if all of the 4500 collected males were sequenced and/or slide-mounted for detailed morphological study. Moreover, one could have analysed all 13,345 specimens to get a more detailed picture of the

Table 1 Summary of sequenced Chironomidae specimens and recognised barcode clusters

\begin{tabular}{|c|c|c|c|}
\hline $\begin{array}{l}\text { Sequenced } \\
\text { individuals }\end{array}$ & $\begin{array}{l}\text { Recognised } \\
\text { morphospecies }\end{array}$ & $\begin{array}{l}\text { Recognised } \\
\text { barcode } \\
\text { clusters }\end{array}$ & $\begin{array}{l}\text { Barcode } \\
\text { clusters represented } \\
\text { by one sex only }\end{array}$ \\
\hline 304 & 71 & 73 & 41 \\
\hline 98 & - & 59 & 27 \\
\hline 402 & 71 & 100 & - \\
\hline
\end{tabular}


contribution females make to the species diversity at the sampled springs and spring brooks. However, we believe that our selection of specimens through a qualitative morphospecies approach reveals a clear tendency in the collected material, and that including females in biodiversity assessments of Chironomidae communities is more effective than relying solely on males despite the current difficulties with species-level identification. As the DNA barcode library of Chironomidae grows and approaches completion, rapid routine identification of all chironomid life stages to species will come within reach for most freshwater diversity assessments. This will allow taxonomists to direct their efforts towards the resolution of taxonomically challenging species and species groups through an integrative-taxonomy approach. The review below offers an idea of the more challenging taxonomic issues that we faced in our comparatively small study involving relatively few species of non-biting midges.

Taxonomy and ecology

\section{Tanypodinae}

Prior to the present study, Procladius cf. ruris Roback, 1971 and Ablabesmyia aspera (Roback, 1959) had not been recorded in Norway or Europe (Sæther and Spies 2004). The two species are only represented in our samples by one male and one female, respectively (Fig. 1), but both cluster with conspecific males collected in Churchill, Manitoba, in a larger barcode dataset (not shown). More than 20 Nearctic and about 60 Palaearctic Procladius species have been described (Murray and Fittkau 1989; Roback 1971), but the long-needed revision of this genus might result in as many as 40 of the corresponding names falling as junior synonyms (Murray and Fittkau 1989). In the latter context, the identification of our specimen as P. ruris might change as well.

\section{Orthocladiinae}

Both Bryophaenocladius and Smittia are taxonomically diverse genera, in which most species probably have terrestrial or semi-terrestrial immature stages (Cranston et al. 1989). At least some arctic species of Smittia are known to be parthenogenetic, e.g. S. brevipennis (Boheman, 1856) and S. velutina (Lundbeck, 1898). Only one of three Smittia species, S. nudipennis (Goetghebuer, 1913), is represented by males in our dataset, but the number of sampled specimens is too low to determine whether the other two species are parthenogenetic or otherwise strongly female-biased.

Three species of an unrecognisable genus of Orthocladiinae (Genus A) were represented by females only.
Morphologically, the specimens are similar to described females in the genera Tavastia, Parasmittia and Gymnometriocnemus, but they do not fit any of the present generic diagnoses.

Chaetocladius is a relatively species-rich genus with about 25 recognised species in Europe. It has never been revised, and new findings have often been grouped with the most similar species descriptions. In our collections we have seven different species, of which two are represented by females only. Our Chaetocladius sp. 2 is morphologically similar to C. laminatus Brundin, 1947 in having a broadly triangular gonostylus, but diverges in some details such as a broader anal point, a less crenulate median margin of the gonostylus, and slightly different setation of the anal tergite and gonostylus (see Brundin 1947, fig. 50).

In addition to Gymnometriocnemus brumalis (Edwards, 1929) and G. volitans (Goetghebuer, 1940), we found two unidentified species of the genus represented only by females. Three of the five known European species have been recorded in Norway (Sæther and Spies 2004), and we have a DNA barcode of the third of these species, $G$. subnudus (Edwards, 1929), from a different locality. Since the genetic distances between our unknown females and the identified males range between $6 \%$ and $15 \%$, we suspect that the two unidentified female species represent taxa so far unknown from Norway. The genus Gymnometriocnemus is characterised as "probably species-poor" in the Holarctic region (Cranston et al. 1989). Our data indicate higher species diversity than expected, and we suspect that future investigations of terrestrial and semi-terrestrial habitats will substantially increase the number of species in this genus.

Our single specimen belonging to the genus Krenosmittia keys to K. boreoalpina (Goetghebuer, 1944) in Tuiskunen and Lindeberg (1986) and is morphologically very similar to two males collected from springs in Luxemburg and the German Alps. However, the former differs from the latter two by COI K2P genetic distances of $8.4 \%$ and $7.8 \%$, respectively, while the specimen from Luxemburg differs from the German one by $10 \%$. Thus, these specimens that are currently all assigned to $K$. boreoalpina likely represent more than a single species. Krenosmittia boreoalpina was originally described from one male collected in the Austrian Alps (Goetghebuer 1944). We therefore regard the specimen from the German Alps as closest to the true $K$. boreoalpina and leave the Sølendet specimen undetermined at species level. The larvae of Krenosmittia are cold-stenothermic and typically inhabit springs and cold streams and rivers (Cranston et al. 1989).

A total of 11 Limnophyes species have been recorded and sequenced in the present study, among which Limnophyes sp. $1, L$. sp. 2 and $L$. sp. 3 are new to science. The 
Fig. 1 Neighbour joining identification tree based on $\mathrm{K} 2 \mathrm{P}$ genetic distances. Numbers on branches are bootstrap values $>50 \%$
100
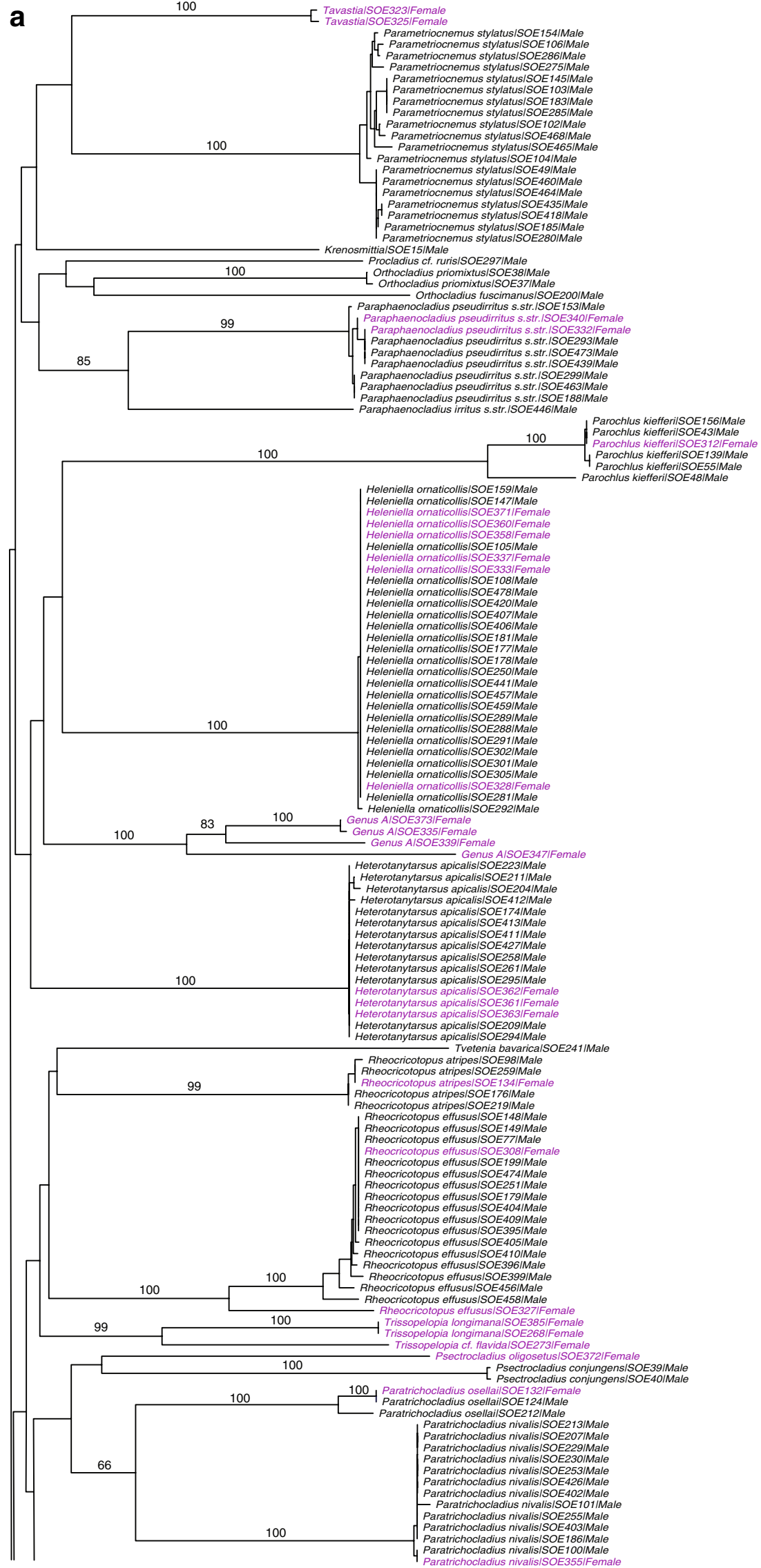
Fig. 1 (continued)

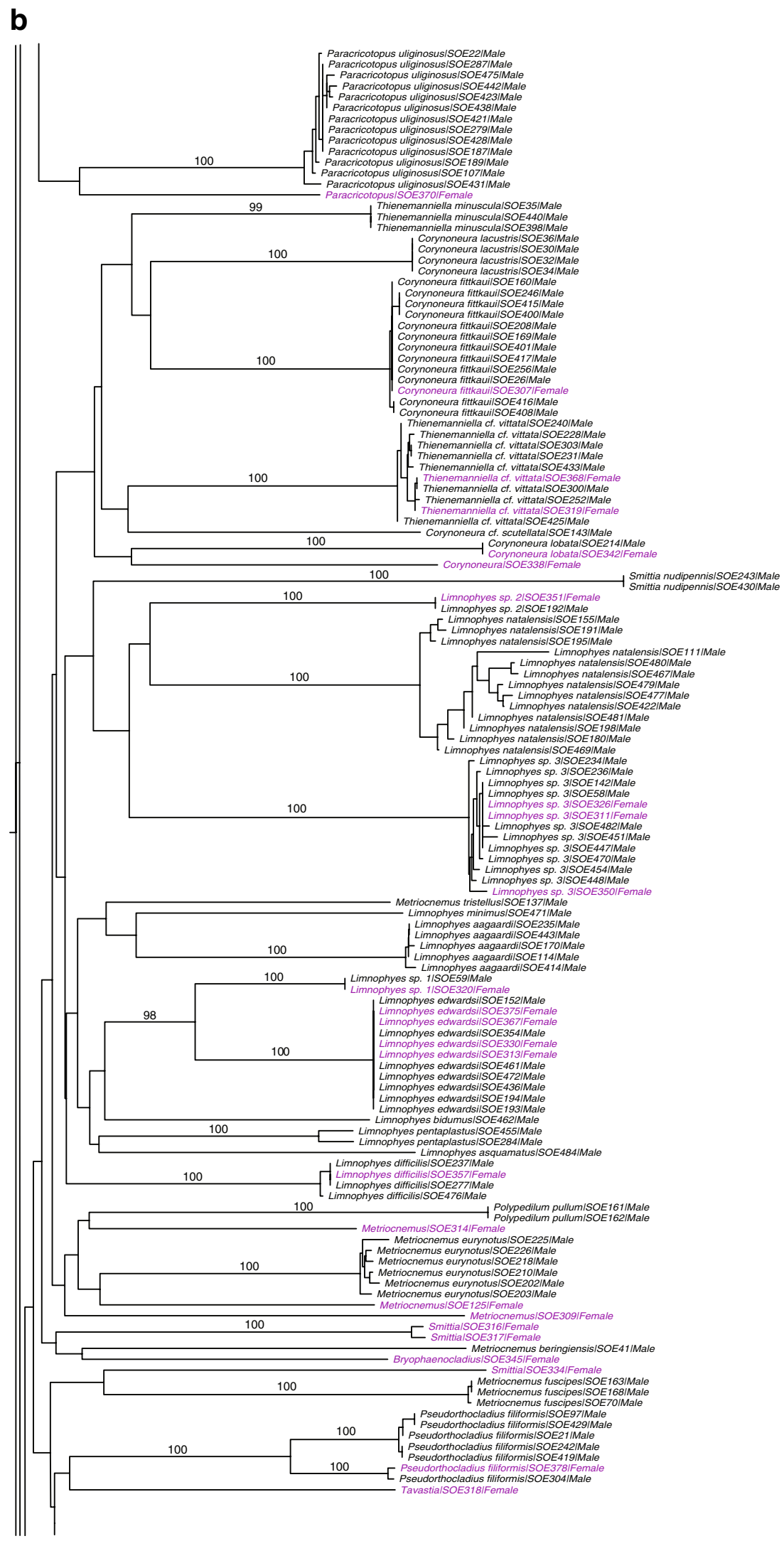


Fig. 1 (continued)

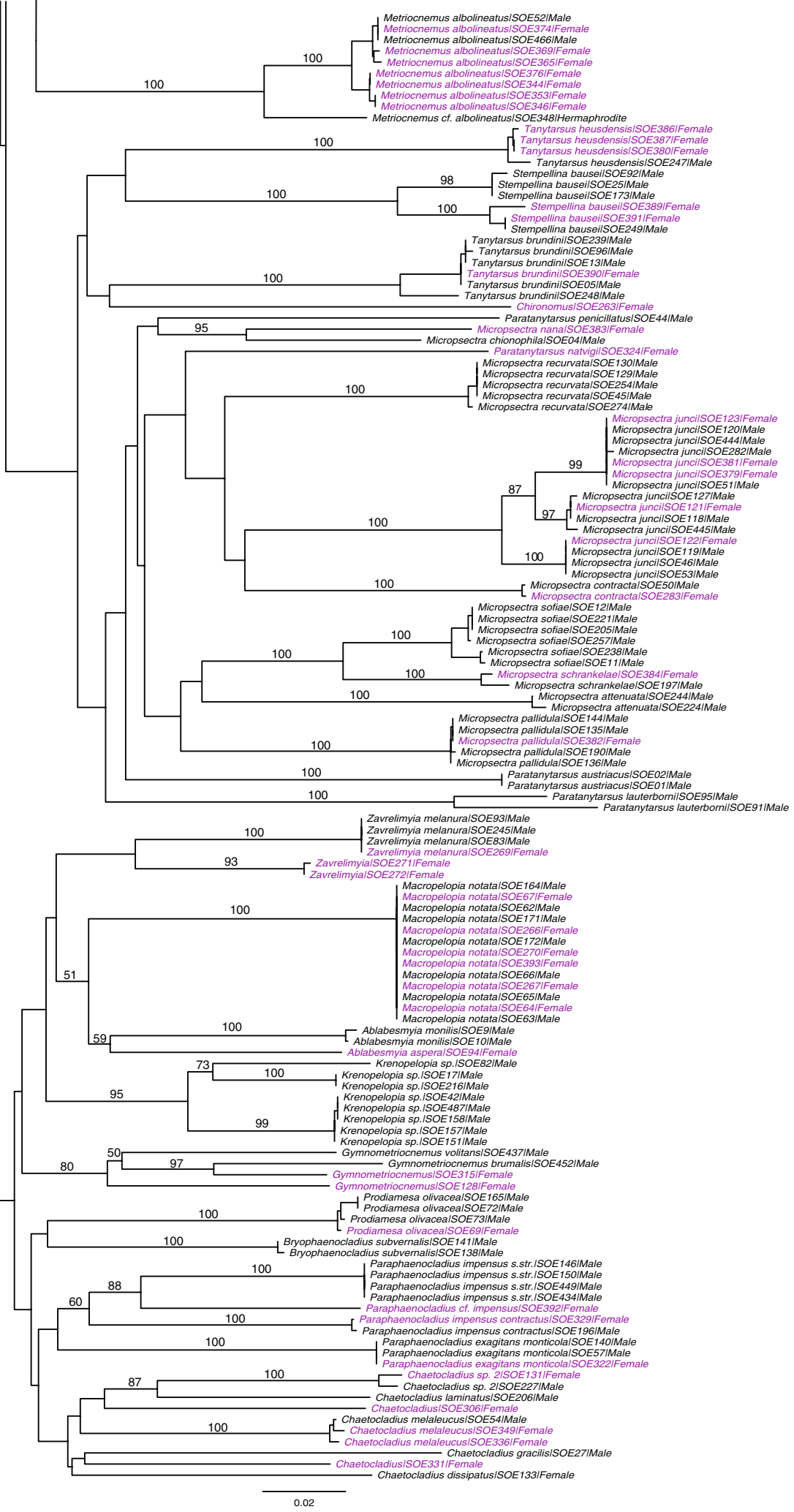


genus has a worldwide distribution and larval habitats range from truly aquatic to terrestrial (Cranston et al. 1989). Most species are small and many occur in the Arctic, high mountains and/or spring habitats. Seventeen valid species have been recorded from the Norwegian mainland and Svalbard (Sæther and Spies 2004). Sæther's (1990) review of the genus presented 14 new species and provided a key to nearly 40 Holarctic and Afrotropical species. Since then, various new species have been described, especially from Asia and Russia (Przhiboro and Sæther 2007 and references therein).

The genus Metriocnemus is represented by seven species in our dataset. Two of these are based on females which we could not associate to any male or identify to species using the available literature. In his comprehensive study on Metriocnemus, Sæther (1989, 1995) revised numerous Holarctic species. Using the keys and diagnoses in this publication, we could positively identify males of $M$. albolineatus (Meigen, 1818), M. beringiensis Cranston \& Oliver, 1988, M. eurynotus (Holmgren, 1883), M. fuscipes (Meigen, 1818), and M. tristellus Edwards, 1929. Previously, M. tristellus had not been recorded from Norway (Sæther and Spies 2004). Comparison with DNA barcodes of Metriocnemus species from other localities revealed some interesting findings for $M$. fuscipes and M. eurynotus: Both morphospecies include multiple genetically divergent clusters. Specimens fitting the morphological description of M. fuscipes are placed in four different clusters, with the specimens from Sølendet in one cluster, specimens from Rondane (Norway) in another, and specimens from the German Alps in the remaining two. Sæther (1989: 423) stated that " $M$. fuscipes is a well defined species and there appears to be no need for designation of a neotype". Our results indicate otherwise, i.e. that some of the currently seven junior synonyms (Sæther 1989) might have to be revalidated or that descriptions of new species might even be necessary. A similar situation exists with M. eurynotus. The specimens that fit the most recent morphological description of this species belong to four different COI clusters. The male specimens from Sølendet are almost identical to specimens from Iceland, while specimens from Svalbard group with specimens from Rondane, and $M$. eurynotus from the German Alps constitute two additional, separate clusters. Sæther (1989: 410) introduced eight new synonyms for $M$. eurynotus but stated that "there is a large variation within the species which might indicate that more than one species is involved." Our data supports the presence of multiple species within the currently accepted morphospecies $M$. eurynotus. Even though multiple, well separated clusters are not observed in the species $M$. albolineatus, one specimen (a hermaphrodite) shows considerable genetic difference (min. 4.7\%) from the other sequenced members of this species. Metriocnemus alboli- neatus is relatively well defined within its genus (Sæther 1989, 1995), and our morphological identification of the hermaphrodite is tentative due to the mixture of male and female characters observed in this specimen.

Most Paraphaenocladius larvae live in terrestrial or semi-aquatic habitats (Cranston et al. 1989). The adults are very similar morphologically, and the few features used to differentiate the species show considerable intraspecific variation. It seems that pupae are easier to separate, but only few pupal morphotypes have been associated to any name-bearing males (Sæther and Wang 1995). Due to the lack of adult characters that would be diagnostic at the species level, several subspecies have been erected for taxa that are morphologically variable and geographically widespread. The Sølendet samples contained six species of Paraphaenocladius. A single female was identified to $P$. impensus s. str. with the key to known females by Sæther and Wang (1995) but is slightly different from those authors' description of the subspecies in being smaller and having fewer setae on the thorax and genitalia. However, the key only contains half of all species and subspecies known in Paraphaenocladius. Hence, with the DNA barcode of our specimen being $>10 \%$ divergent from males of $P$. impensus s.str. (Fig. 1), that female probably belongs to a different subspecies. The other taxa recognised in our samples are: $P$. impensus subsp. contractus, $P$. exagitans subsp. monticola, P. pseudirritus s. str., and P. irritus s. str. The DNA barcodes indicate considerable genetic distance between the subspecies, so that the latter probably should be raised to species. Comparison of the Sølendet data to the DNA barcodes of Paraphaenocladius species from other projects (not shown) reveal more diversity, with 17 well separated clusters within this genus. Five of these groups contain specimens that fit the current definition of $P$. impensus sensu lato, and even within the subspecies $P$. impensus s. str. and $P$. pseudirritus s. str. there are clusters showing high genetic divergence $(>10 \%)$.

The genus Paratrichocladius has 11 registered species in Europe, ten of which were partly revised by Rossaro (1990, 1991). Adult males of species in the P. skirwithensis group are extremely similar and unpublished data on presumably intraspecific variation indicate that there could be one or more cases of synonymy (Bruno Rossaro and Peter $\mathrm{H}$. Langton pers. comm.). For one of our species we have a barcode-associated pupa from the Atna watershed (Norway) which fits the description of $P$. osellai sensu Langton and Visser (2003). Specimens of the other Paratricocladius species at Sølendet best fit $P$. nivalis as described by Rossaro (1991). Both species are new to Norway and associated with cold springs, brooks and streams (Rossaro 1991).

Pseudorthocladius filiformis (Kieffer, 1908) belongs to the $P$. filiformis species group, which contains at least six 
Holarctic species (Sæther and Sublette 1983) some of which are only separable as pupae. There is about $5 \%$ difference between the sampled specimens of this species, but the COI sequences of $P$. filiformis from Sølendet are more than $13 \%$ different from those of P. curtistylus (Goetghebuer, 1922) that we have sampled from the Atna watershed. Pseudorthocladius curtistylus and P. filiformis so far are the only two European members of this species group, but they can be difficult to separate as adult males (Sæther and Sublette 1983). Until more material (including immature stages) is examined and barcoded we regard the observed $5 \%$ sequence difference as intraspecific variation in P. filiformis. Immatures of Pseudorthocladius are associated with damp habitats such as mosses, seeps and floodplains along stream banks (Cranston et al. 1989).

The species Rheocricotopus effusus (Walker, 1856) shows the largest intraspecific variation in COI observed by us, with one female specimen slightly less than $6 \%$ different from the others. Based on the review by Sæther (1985), our specimens fit the description of $R$. effusus. The barcode from the divergent female from Sølendet is almost identical to the barcode of a male $R$. effusus from the Atna watershed and the high genetic divergence within this group might indicate cryptic species. Rheocricotopus effusus has been found to inhabit springs, brooks and cold streams (Lehmann 1969).

Our record of the genus Tavastia is the first from Norway. The genus was first described from northern Fennoscandia by Tuiskunen (1985), but additional species have been recorded from the USA (one species) and northern Europe (two species) (Brodin et al. 2008). All species are found in wetlands or spring habitats. Our two females fit the generic diagnosis and resemble the only described female in the genus, T. yggdrasilia Brodin et al., 2008. However, because they do not completely fit the latter species diagnosis and description, we leave them as an undetermined species in the genus Tavastia.

\section{Chironominae}

The taxonomy of species in the genus Parapsectra was recently revised (Giłka and Jażdżewska 2010) and our record of P. chionophila (Edwards, 1933) is just the second from Norway. This species is relatively poorly known, but presumed to be cold-stenothermic in springs, brooks, moorland pools and peat bogs (Giłka and Jażdżewska 2010). In results from recent molecular phylogenetic analyses, species of the genus Parapsectra formed several groups within the larger genus Micropsectra (Ekrem et al. 2010). Consequently, we treat Parapsectra as a junior synonym of Micropsectra and all species of the former genus in the latter.

\section{Conclusions}

DNA barcoding enables the inclusion of all life stages in biodiversity assessments. In the species-rich family of Chironomidae, this is important for accurate measures of diversity in semi-terrestrial and aquatic ecosystems. The inclusion of females in our qualitative study of non-biting midges in springs and spring brooks substantially increased the total number of recorded species. Moreover, DNA barcoding enabled the association of females with males from other localities and revealed interesting complexities in the taxonomy of several species and genera. The comparatively high proportion of unassociated females in our dataset may reflect male-dominated taxonomic information in combination with the presence of parthenogenetic species, biased sex ratios or general species rarity. We conclude that the inclusion of female chironomids, particularly at sites with many rare species, female-biased sex ratios, or when sample sizes are small, will greatly aid comprehensive species coverage.

Acknowledgements Thanks to Kaare Aagaard for project initiation, to Oddvar Hanssen, Otto Frengen and Kaare Aagaard for field and laboratory assistance, and to Alex Borisenko, Xin Zhou and the remaining staff at the CCBD for help with sequencing and databasing. Thanks also to the Røros Municipality for permits to collect insects in the Sølendet Nature Reserve. The Royal Norwegian Society of Sciences and Letters funded part of the field work. Sequence analysis was enabled by support from Genome Canada through the Ontario Genomics Institute to Paul Hebert. Part of this work was carried out using resources of the Computational Biology Service Unit at Cornell University which is partially funded by Microsoft Corporation.

Open Access This article is distributed under the terms of the Creative Commons Attribution Noncommercial License which permits any noncommercial use, distribution, and reproduction in any medium, provided the original author(s) and source are credited.

\section{References}

Aagaard, K., Solem, J. O., Bongard, T., \& Hanssen, O. (2004). Studies of aquatic insects in the Atna River 1987-2002. Hydrobiologia, 521, 87-105.

Armitage, P. D., Cranston, P. S., \& Pinder, L. C. V. (1995). The Chironomidae. Biology and ecology of non-biting midges. London: Chapman \& Hall.

Bensasson, D., Zhang, D. X., Hartl, D. L., \& Hewitt, G. M. (2001). Mitochondrial pseudogenes: evolution's misplaced witnesses. Trends in Ecology and Evolution, 16, 314-321.

Blackwood, M. A., Hall, S. M., \& Ferrington, L. C., Jr. (1995). Emergence of Chironomidae from springs in the Central High Plains Region of the United States. Journal of the Kansas Entomological Society, 68, 132-151.

Blaxter, M. L. (2004). The promise of a DNA taxonomy. Philosophical Transactions of the Royal Society of London / Series B / Biological Sciences, 359, 669-679. 
Brodin, Y., Lundstrøm, J. O., \& Paasivirta, L. (2008). Tavastia yggdrasilia, a new orthoclad midge (Diptera: Chironomidae) from Europe. Aquatic Insects, 30, 261-267.

Brundin, L. (1947). Zur Kenntnis der schwedischen Chironomiden. Arkiv för Zoologi, 39 A, 1-95.

Brundin, L. (1949). Chironomiden und andere Bodentiere der südschwedischen Urgebirgsseen. Ein Beitrag zur Kenntnis der bodenfaunistischen Charakterzüge schwedischer oligotropher Seen. Lund, Drottningholm: Institute of Freshwater Research.

Carew, M. E., Pettigrove, V., \& Hoffmann, A. A. (2005). The utility of DNA markers in classical taxonomy: using cytochrome oxidase I markers to differentiate Australian Cladopelma (Diptera: Chironomidae) midges. Annals of the Entomological Society of America, 98, 587-594.

Carew, M. E., Pettigrove, V., Cox, R. L., \& Hoffmann, A. A. (2007). DNA identification of urban Tanytarsini chironomids (Diptera: Chironomidae). Journal of the North American Benthological Society, 26, 587-600.

Caterino, M. S., \& Tishechkin, A. K. (2006). DNA identification and morphological description of the first confirmed larvae of Hetaeriinae (Coleoptera: Histeridae). Systematic Entomology, $31,405-418$

Cranston, P. S., Oliver, D. R., \& Sæther, O. A. (1989). The adult males of Orthocladiinae (Diptera: Chironomidae) of the Holarctic region-keys and diagnoses. In: T. Wiederholm (Ed.), Chironomidae of the Holarctic region. Keys and diagnoses. Part 3-adult males (pp. 165-352). Sandby: Entomologica scandinavica Supplement, 34.

Ekrem, T., Willassen, E., \& Stur, E. (2007). A comprehensive DNA sequence library is essential for identification with DNA barcodes. Molecular Phylogenetics and Evolution, 43, 530-542.

Ekrem, T., Willassen, E., \& Stur, E. (2010). Phylogenetic utility of five genes for dipteran phylogeny: a test case in the chironomidae leads to generic synonymies. Molecular Phylogenetics and Evolution, 57 (2), 561-571

Fittkau, E. J. (1962). Die Tanypodinae (Diptera: Chironomidae) (Die Tribus Anatopyniini, Macropelopiini und Pentaneurini). Abhandlungen zur Larvalsystematik der Insekten, 6, 1-453.

Folmer, O., Black, M., Hoeh, W., Lutz, R., \& Vrijenhoek, R. (1994). DNA primers for amplification of mitochondrial cytochrome c oxidase subunit I from diverse metazoan invertebrates. Molecular Marine Biology and Biotechnology, 3, 294-299.

Funk, D. J., \& Omland, K. E. (2003). Species-level paraphyly and polyphyly: Frequency, causes, and consequences, with insights from animal mitochondrial DNA. Annual Review of Ecology, Evolution, and Systematics, 34, 397-423.

Giłka, W., \& Jażdżewska, N. (2010). A systematic review of the genus Parapsectra Reiss (Diptera: Chironomidae: Tanytarsini) with description of a new species from Poland. Zootaxa, 2350, $1-21$.

Giłka, W., \& Paasivirta, L. (2008). On the systematics of the tribe Tanytarsini (Diptera: Chironomidae) - three new species from Finland. Entomologica Fennica, 19, 41-48.

Goetghebuer, M. (1944). Ceratopogonidae et Chironomidae nouveaux ou peu connus d'Europe (Douzième Note). Biologisch Jaarboek, $11,35-44$.

Golding, G. B., Hanner, R., \& Hebert, P. D. N. (2009). Preface. Special issue on DNA barcoding. Molecular Ecology Resources, 9, iv-vi.

Hebert, P. D. N., Cywinska, A., Ball, S. L., \& deWaard, J. R. (2003). Biological identifications through DNA barcodes. Proceedings of the Royal Society of London / B, 270, 313-321.

Hebert, P. D. N., Penton, E. H., Burns, J. M., Janzen, D. H., \& Hallwachs, W. (2004). Ten species in one: DNA barcoding reveals cryptic species in the neotropical skipper butterfly Astraptes fulgerator. Proceedings of the National Academy of Sciences of the United States of America, 101, 14812-14817.
Huelsenbeck, J. P., \& Ronquist, F. (2001). MrBayes: Bayesian inference of phylogeny. Bioinformatics, 17, 754-755.

Jones, F. C. (2008). Taxonomic sufficiency: the influence of taxonomic resolution on freshwater bioassessments using benthic macroinvertebrates. Environmental Review, 16, 45-69.

Langton, P. H. (1999). Micropsectra silvesterae n. sp. and Tanytarsus heliomesonyctios n. sp., (Diptera: Chironomidae), two parthenogenetic species from Ellesmere Island, Arctic Canada. Journal of the Kansas Entomological Society, 71, 208-215.

Langton, P. H., \& Visser, H. (2003). Chironomidae exuviae. A key to pupal exuviae of the West Palaearctic Region. CD-ROM. Amsterdam: Biodiversity Center of ETI.

Langton, P. H., \& Pinder, L. C. V. (2007). Keys to the adult male Chironomidae of Britain and Ireland. Ambleside: Freshwater Biological Association.

Lehmann, J. (1969). Die europäischen Arten der Gattung Rheocricotopus Thien. und Harn. und drei neue Artvertreter dieser Gattung aus der Orientalis (Diptera, Chironomidae). Archiv für Hydrobiologie, 66, 348-381.

Linares, M. C., Soto-Calderon, I. D., Lees, D. C., \& Anthony, N. M. (2009). High mitochondrial diversity in geographically widespread butterflies of Madagascar: a test of the DNA barcoding approach. Molecular Phylogenetics and Evolution, $50,485-495$.

Lindeberg, B. (1971). Parthenogenetic strains and unbalanced sex ratios in Tanytarsini (Diptera, Chironomidae). Annales Zoologici Fennici, 8, 310-317.

Moen, A. (1990). The plant cover of the boreal uplands of Central Norway. I. Vegetation ecology of Sølendet Nature Reserve; haymaking fens and birch woodlands. Trondheim: Norwegian University of Science and Technology. Museum of Natural History and Archaeology.

Murray, D. A., \& Fittkau, E. J. (1989). The adult males of Tanypodinae (Diptera: Chironomidae) of the Holarctic regionKeys and diagnoses. In: T. Wiederholm (Ed.), Chironomidae of the Holarctic region. Keys and diagnoses. Part 3-Adult males (pp. 37-123). Entomologica scandinavica Supplement, 34.

Pegg, G. G., Sinclair, B., Briskey, L., \& Aspden, W. J. (2006). MtDNA barcode identification of fish larvae in the southern Great Barrier Reef, Australia. In M. P. Olivar \& J. J. Govoni (Eds.), Recent advances in the study of fish eggs and larvae (pp. 7-12). Barcelona: Scientia Marina.

Pfenninger, M., Nowak, C., Kley, C., Steinke, D., \& Streit, B. (2007). Utility of DNA taxonomy and barcoding for the inference of larval community structure in morphologically cryptic Chironomus (Diptera) species. Molecular Ecology, 16, 1957-1968.

Posada, D., \& Crandall, K. A. (1998). MODELTEST: testing the model of DNA substitution. Bioinformatics, 14, 817-818.

Przhiboro, A., \& Sæther, O. A. (2007). Limnophyes (Diptera: Chironomidae) from northwestern Russia. Aquatic Insects, 29, 49-58.

Rambaut, A. (2009). FigTree. Tree figure drawing tool, 1.2.2. Edinburgh: Institute of Evolutionary Biology, University of Edinburgh. http://tree.bio.ed.ac.uk/. Accessed 1 April 2010.

Ratnasingham, S., \& Hebert, P. D. N. (2007). BOLD: The barcode of life data system (www.barcodinglife.org). Molecular Ecology Notes, 7, 355-364.

Raunio, J., \& Muotka, T. (2005). The use of chironomid pupal exuviae in river biomonitoring: the importance of sampling strategy. Archiv für Hydrobiologie, 164, 529-545.

Raunio, J., Paavola, R., \& Muotka, T. (2007). Effects of emergence phenology, taxa tolerances and taxonomic resolution on the use of the Chironomid Pupal Exuvial Technique in river biomonitoring. Freshwater Biology, 52, 165-176.

Roback, S. S. (1971). The adults of the subfamily Tanypodinae (Pelopiinae) in North America (Diptera: Chironomidae). Monographs of the Academy of Natural Sciences of Philadelphia, 17, 1-410. 
Ronquist, F., \& Huelsenbeck, J. P. (2003). MRBAYES 3: Bayesian phylogenetic inference under mixed models. Bioinformatics, 19 , $1572-1574$.

Rossaro, B. (1990). Revision of the genus Paratrichocladius SantosAbreu. 2nd note: description of 4 new species (Diptera Chironomidae Orthocladiinae). Bollettino della Società Entomologica Italiana, 122, 58-60.

Rossaro, B. (1991). Paratrichocladius nivalis (Goetgh.) described with observations on the taxonomic status of the species (Diptera Chironomidae). Bollettino di Zoologia agraria e di Bachicoltura, Serie II, 23, 9-20.

Rubinoff, D., Cameron, S., \& Will, K. (2006). A genomic perspective on the shortcomings of mitochondrial DNA for "Barcoding" identification. Journal of Heredity, 97, 581-594.

Sæther, O. A. (1977). Female genitalia in Chironomidae and other Nematocera: morphology, phylogenies, keys. Bulletin of the Fisheries Research Board of Canada, 197, 1-209.

Sæther, O. A. (1983). A review of Holarctic Gymnometriocnemus Goetghebuer, 1932, with the description of Raphidocladius subgen. n. and Sublettiella gen. n. (Diptera: Chironomidae). Aquatic Insects, 5, 209-226.

Sæther, O. A. (1985). A review of the genus Rheocricotopus Thienemann \& Harnisch, 1932, with the description of three new species (Diptera: Chironomidae). Spixiana Supplement, 11, 59-108.

Sæther, O. A. (1989). Metriocnemus van der Wulp: a new species and a revision of species described by Meigen, Zetterstedt, Stæger, Holmgren, Lundström and Strenzke (Diptera: Chironomidae). Entomologica scandinavica, 19, 393-430.

Sæther, O. A. (1990). A review of the genus Limnophyes Eaton from the Holarctic and Afrotropical regions (Diptera: Chironomidae, Orthocladiinae). Entomologica scandinavica Supplement, 35, 1-139.

Sæther, O. A. (1995). Metriocnemus van der Wulp: seven new species, revision of species, and new records (Diptera: Chironomidae). Annales de Limnologie, 31, 35-64.

Sæther, O. A. (2000). Aagaardia, a new holarctic orthoclad genus (Diptera: Chironomidae). Aquatic Insects, 22, 177-196.

Sæther, O. A., \& Sublette, J. E. (1983). A review of the genera Doithrix n. gen., Georthocladius Strenzke, Parachaetocladius Wülker and
Pseudorthocladius Goetghebuer (Diptera: Chironomidae, Orthocladiinae). Entomologica scandinavica Supplement, 20, 1-100.

Sæther, O. A., \& Wang, X. H. (1995). Revision of the genus Paraphaenocladius Thienemann, 1924 of the world (Diptera, Chironomidae, Orthocladiinae). Entomologica scandinavica Supplement, 48, 1-69.

Sæther, O. A., \& Spies, M. (2004). Fauna Europaea: Chironomidae. In: H. de Jong (Ed.), Fauna Europaea: Diptera: Nematocera. Fauna Europaea version 1.2. http://www.faunaeur.org/. Accessed 1 April 2010.

Scholl, H. (1960). Die Oogenese einiger parthenogenetischer Orthocladiinen (Diptera). Chromosoma, 11, 380-401.

Sinclair, C. S., \& Gresens, S. E. (2008). Discrimination of Cricotopus species (Diptera: Chironomidae) by DNA barcoding. Bulletin of Entomological Research, 98, 555-563.

Stoeckle, M. (2003). Taxonomy, DNA, and the bar code of life. Bioscience, 53, 796-797.

Stur, E., \& Ekrem, T. (2006). A revision of West Palaearctic species of the Micropsectra atrofasciata species group (Diptera: Chironomidae). Zoological Journal of the Linnean Society, 146, 162-225.

Stur, E., Martin, P., \& Ekrem, T. (2005). Non-biting midges as hosts for water mite larvae in spring habitats in Luxembourg. Annales de Limnologie, 41, 225-236.

Tamura, K., Dudley, J., Nei, M., \& Kumar, S. (2007). MEGA4: Molecular evolutionary genetics analysis (MEGA) software version 4.0. Molecular Biology and Evolution, 24, 1596-1599.

Tuiskunen, J. (1985). Tavastia australis, a new genus and species (Diptera, Chironomidae, Orthocladiinae) from Finland. Annales Entomologici Fennici, 51, 30-32.

Tuiskunen, J., \& Lindeberg, B. (1986). Chironomidae (Diptera) from Fennoscandia north of $68^{\circ} \mathrm{N}$, with a description of ten new species and two new genera. Annales Entomologici Fennici, 23, 361-393.

Wiemers, M., \& Fiedler, K. (2007). Does the DNA barcoding gap exist? - a case study in blue butterflies (Lepidoptera: Lycaenidae). Frontiers in Zoology, 4 (8), 1-16.

Zhou, X., Adamowicz, S., Jacobus, L., DeWalt, R. E., \& Hebert, P. (2009). Towards a comprehensive barcode library for arctic lifeEphemeroptera, Plecoptera, and Trichoptera of Churchill, Manitoba, Canada. Frontiers in Zoology, 6 (30), 1-9. 